\title{
Preparation and Study of Catalysts on Metal blocks for Neutralization of Exhaust Gases of the Stationary Diesel Generator
}

\section{LARISSA SASSYKOVA ${ }^{1 *}$, ARAILYM NALIBAYEVA ${ }^{2}$, YERMEK AUBAKIROV ${ }^{1}$, ZHENETA TASHMUKHAMBETOVA ${ }^{1}$, ULZHAN OTZHAN ${ }^{1}$, NURBUBI ZHAKIROVA ${ }^{1}$ and MARIA FAIZULLAEVA ${ }^{3}$}

${ }^{1}$ Al-Farabi Kazakh National University, 71, al-Farabi ave., 050040, Almaty, Kazakhstan. ${ }^{2}$ D.V.Sokolsky Institute of Fuel, Catalysis \& Electrochemistry, 142, D.Kunaev str., 050010, Almaty, Kazakhstan.

${ }^{3}$ Scientific Research Institute for New Chemical Technologies and Materials, 95a,

Karasaibatyr str., 050012, Almaty, Kazakhstan.

${ }^{*}$ Corresponding author E-mail: larissa.rav@mail.ru

http://dx.doi.org/10.13005/ojc/330440

(Received: May 29, 2017; Accepted: June 20, 2017)

\begin{abstract}
The work aim was preparation of catalysts with various active phase on metal block carriers and test their effectiveness on exhaust gases of the stationary diesel generator at various loadings. The active phase was prepared on the basis of the platinum group metals, oxides of nickel, manganese. The catalyst on the basis of $0.1 \%$ of Pt kept the activity during $100 \mathrm{~h}$. test on the diesel generator. The most effective catalyst at all engine operating conditions was the sample containing $5 \%$ of nickel oxide and manganese and activated of $0.1 \% \mathrm{Pt}$. The catalytic samples on the basis of $\mathrm{Ni}$ and $\mathrm{Mn}$ promoted by $\mathrm{Pd}(0.1 \%, 0.25 \%)$ and $\mathrm{Pt}(0.1 \%)$, provide high degree of conversion of $\mathrm{CO}$ to $\mathrm{CO}_{2}$, $\mathrm{C}_{\mathrm{x}} \mathrm{H}_{\mathrm{y}}$ to $\mathrm{CO}_{2}$ and $\mathrm{H}_{2} \mathrm{O}$, NO to $\mathrm{N}_{2}$.
\end{abstract}

Keywords: exhaust gases, catalysts on the metal blocks, neutralization of emissions, diesel generator

\section{INTRODUCTION}

Reducing air pollution by toxic substances emitted by industrial plants and motor vehicles is one of the most urgent tasks for all industrialized and economically developed countries. A crucial role in air pollution is being played gasoline internal combustion engines. However, the reduction in toxicity of diesel vehicles also deserves serious attention. Diesel engines and diesel generators were widely adopted in all spheres of transport and the industry. Thanks to diesel engines more high level of effectiveness of use of fuel in comparison with gasoline engines is reached: the modern 
diesel units spend fuels for about $30.0 \%$ less, than gasoline motors with direct injection of the same generation ${ }^{1-5}$. Nevertheless, at operation of diesel generators arise the dangerous and harmful factors (noise, vibration, exhaust gases) as a result of which action the ecological situation is broken, the exhaust gases of diesel engines contain significantly higher concentration of solid particles which existence in air can be the cause of some serious illness, including oncological violations, and even premature death ${ }^{6-8}$. It is very important issue of cleaning of exhaust gases in closed spaces where are operated the stationary diesel generators in limited spaces: in the mines, ports, quarries of mines of the opencast mining. Diesel engines are a major source of nitrogen oxides in the atmosphere which causes harmful effects on human health, resulting in the formation of ozone and particulate matters containing carcinogenic substances. The main directions of improvement of diesel engines are reducing of fuel consumption, toxicity of the exhaust emissions, noise level, engine capacity increase, facilitation of cold start. The composition of the exhaust gases of gasoline and diesel is significantly varied. For the engines working at gasoline is characteristic lower content of oxygen, high - of carbon dioxide and especially large - of carbon monoxide.

Among the known methods of disposal and neutralization of harmful emissions of transport the most effective is the deep catalytic oxidation of organic compounds to carbon dioxide and water. The catalysts on block metal or ceramic carriers are the most preferable thanks to the developed surface, a wide choice of options of chemical and design decisions, low difference of pressure, high thermal

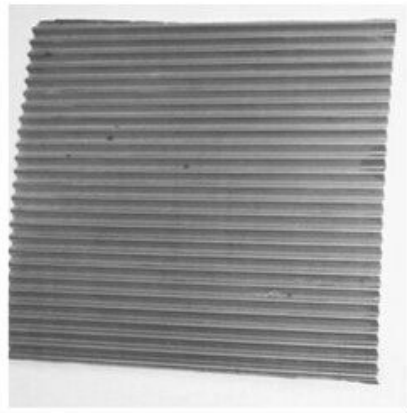

a and mechanical stability. Effective use of metal in the active phase when preparing of catalysts on metal carriers is achieved in case if the active phase is transferred into the highly dispersed condition. Protection of the environment from industrial and transport pollution puts to humanity demands to improve the synthesis methods of the neutralizing catalysts and purification of gas emissions from harmful admixtures ${ }^{9-12}$. The urgency of creating a reliable working neutralizers increases due to necessity of compliance with current environmental standards ${ }^{8,13}$.

The work aim is preparation of full-size catalysts on metal block carriers and test of their effectiveness on exhaust gases of the stationary diesel generator at various loadings.

\section{MATERIALS AND METHODS}

By the technique developed earlier ${ }^{14-16}$ the catalysts on metal block carriers (fig.1) are synthesized. For preparation of metallic carriers for full size samples of catalysts was used the heatresistant foil of 50 microns thick with gauge length and width, which is goffered (fig.1). It applies two types of corrugation. The first type of the corrugations (1a) has the usual form channels, while the 2nd type of the corrugated foil (fig. $1 \mathrm{~b}$ ) is curved at the inlet gas stream in the middle and at the outlet. This form of channels promotes destruction of the laminar gas flow, the formation of turbulence and increases the degree of contact of the unreacted gas molecules with an active catalyst layer. The total length of one channel of foil of the second type (fig.1, b) sample by $5.0 \%$ longer than of the sample of 1 -st

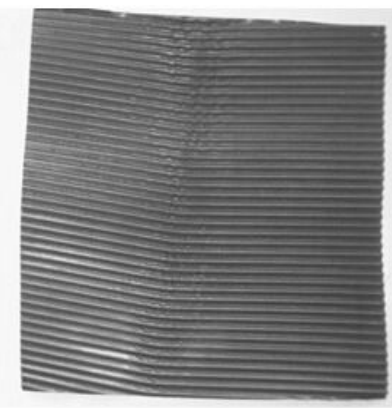

b

Fig. 1: The strips of corrugated foil: with channels of "direct" type (a), with channels of "chevron type" (b) 
type (fig.1,a). The foil is located in vertical position on installation for goffering, goffering is carried out with the help of platens with diameter of $50.0 \mathrm{~mm}$ and length $250.0 \mathrm{~mm}$. The tape is kept in the centre of platens with the help of directing cheeks. On the smooth tape foils is superimposed a corrugated tape, then the strips are folded in the cylinder block and joined by welding contact.

Fig.2 shows block metal carriers with honeycomb structure of channels. The washcoat (secondary carrier) is put on the prepared metal carrier. The washcoat was prepared on the basis of alumina or alumina with additives (compounds of refractory metals or compositions on the basis of zeolites).

During synthesis of catalysts viscosity of suspension on the basis of alumina was defined, its best value for suspension preparation was equal to - 0.02 Pa.sec. Removal surplus of suspension from channels of the block carrier is carried out with use of the Centrifuge CM-6M. It was found experimentally that for the removal of the excess slurry of washcoat from the channels block is required speed of rotation of the centrifuge $600 \mathrm{rev} / \mathrm{min}$., duration rotation-2.0 min. After drying blocks in a furnace the active phase of the catalyst is deposited on the washcoat. The active phase is prepared on the basis of platinum metals, oxides of nickel and manganese by dissolution of compounds of the corresponding metals (nitrates, acetates, formates) in decationized water. Also polyethylene - glycol - PEG-10, 000 for synthesis of the active phase is used. The active phase is deposited on the metal blocks covered with the washcoat by means of impregnation. After that

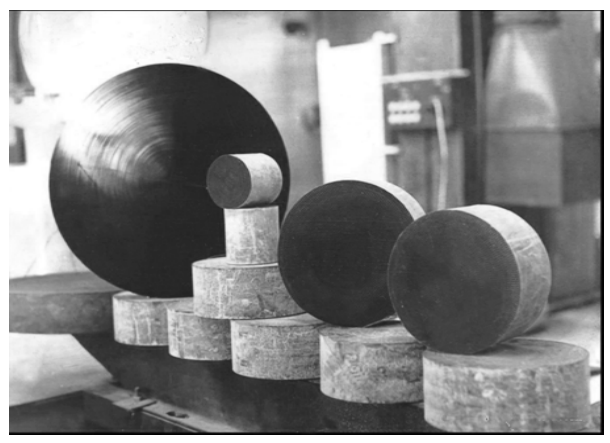

a drying of the impregnated blocks is carried out at a temperature of $473 \mathrm{~K}$ during $4 \mathrm{~h}$. and calcination of samples at $773 \mathrm{~K}$ during $2 \mathrm{~h}$. Some of samples of catalysts was promoted with an aqueous solution of $\mathrm{PdCl}_{2}$, of $0.2 \%$ by weight, the other part of catalysts was promoted by $\mathrm{Pt}$, of $0.1 \%$ by weight.

For testing the efficiency of the catalysts was used the stand on the basis of diesel generator of brand 5GF-LDE with power of 5 kVA (fig.3, 4). The full-size catalyst samples had a diameter of $30.0 \mathrm{~mm}$, a height of $90.0 \mathrm{~mm}$. The catalyst was loaded into the gas-abstersive off shoot of the diesel generator. Temperature before and after the catalyst is defined with use of a chromel-alumel thermocouple outputted on the digital indicator. Gas mixture was analyzed by means of GLC and on a gas analyzer "OPTOGAS 500" before and after the reaction. The chromatographs "Crystal 2000M" and "Chrom 3700" with a flame ionization detector were used. Analysis duration was equal to 20-30 min. Previously the catalyst was calcined at $773 \mathrm{~K}$ for 4 h. in air in a muffle furnace.

\section{RESULTS AND DISCUSSION}

Tests were carried out on all modes of operation of the engine of the diesel generator (at no-load operation (idling), at 1.0; 2.0; 3.0; 4.0 kVA). The results of triple tests of catalysts are presented in Table 1. With an increasing number of engine revolutions per minute from 420.0 to 820.0 temperature rise is observed from 491 to $851 \mathrm{~K}$ and increase of carbon monoxide content from 0.08 to $0.26 \%$. The content of hydrocarbons at the same time was varied within $0.002-0.008,4 \mathrm{vol} . \%$. The analysis

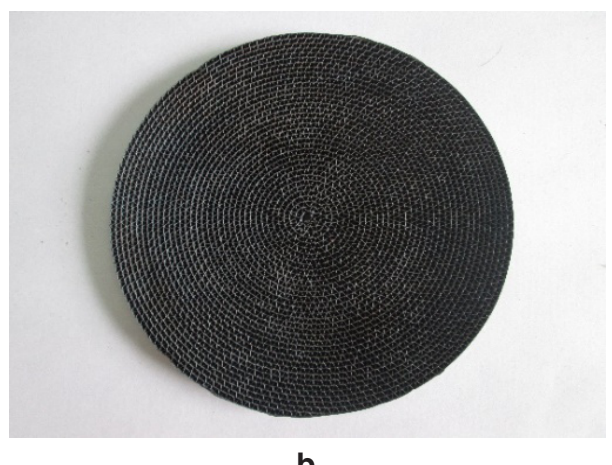

b

Fig. 2: The full-size catalytic converters on block metal carrier: a - perspective view, b - cross-sectional view 
of exhaust gases before and after the catalyst showed that the lowest percentage of oxidation of harmful components was characteristic of modes of engine power - up to $5.0 \mathrm{kVA}$, revolutions per min. - to 490.0, when the gases have a low temperature (up to $553 \mathrm{~K}$ ). With increasing of engine load the degree of deep oxidation of harmful components increased and stored in the area of $\mathrm{CO}$ values - from 40.0 to $90.0 \%$, hydrocarbons from 35.0 to $100 \%$ for nitrogen oxides from 10.0 to $40.0 \%$. Thus, the synthesized catalysts at $473 \mathrm{~K}$ and higher provide a high performance in stand tests.

Bench tests of three catalysts (on the basis of Ni-Mn promoted by Pd (0.1-0.2 wt.\%) and Pt (0.1 wt.\%) are carried out.

Tables 2, 3 show the test data. It is found that in $\mathrm{CO}$ oxidizing reaction the catalyst containing $0.2 \%$ of $\mathrm{Pd}$ is more active, than the catalyst on the basis of $\mathrm{Mn}$ and $\mathrm{Ni}$ oxides. Under identical test conditions in reactions of reduction of nitrogen oxides and oxidations of hydrocarbons activity of catalysts on the basis of $\mathrm{Pd}$ and $\mathrm{Mn}$ and $\mathrm{Ni}$ oxides is almost identical. High selectivity on $\mathrm{NO}_{\mathrm{x}}$ was observed at higher loadings of the engine (3.0-4.0 kVA) where temperature reached $600-700 \mathrm{~K}$.

Catalysts based on palladium and platinum with a promoting additives were tested for thermal stability under load of diesel generator 3.0 kVA. During the 100-h. test with fractional neutralizers calcination at $873 \mathrm{~K}$ at an interval of $5 \mathrm{~h}$. in a muffle furnace it was found that the introduced structural and textural thermo stabilizing additives into the catalysts promote a sustainable activity (tab.4).

Diesel exhaust is a mixture of coarsely dispersed aerosol with a particle size of $0.5-1.0$ microns ${ }^{14,17-19}$. The disperse phase of the same mixed aerosol has complex composition and consists of liquid and resinous and solid unburned products. Experiments carried out on the diesel generator in this investigation showed that in the diesel exhaust at all engine operation modes is formed soot with the predominant size of particles 0.4-5.0 micrometres. The speed of these particles reached $20 \mathrm{~m} / \mathrm{s}$, and the temperature $-673 \mathrm{~K}$. Primary structures of the soot

Table 1: The effectiveness of the complex cleaning of exhaust gases on the full-size block catalysts on the basis of 0.1 and $0.25 \% \mathrm{Pd}, 0.1 \% \mathrm{Pt}$

\begin{tabular}{|c|c|c|c|c|c|c|c|c|c|c|c|}
\hline \multirow{2}{*}{$\begin{array}{l}\text { Number } \\
\text { of rev/ } \\
\text { min. } \\
\text { (at } \\
\text { different } \\
\text { power, } \\
\text { kVA) }\end{array}$} & \multirow{2}{*}{$\begin{array}{l}\text { Counter, } \\
\text { pressure } \\
\text { mm of a } \\
\text { hydrogen } \\
\text { column }\end{array}$} & \multirow{2}{*}{$\begin{array}{l}\text { Tempe, } \\
\text { rature - } \\
\mathrm{K}\end{array}$} & \multicolumn{5}{|c|}{ CO, ppm } & \multicolumn{2}{|c|}{$\mathrm{C}_{\mathrm{x}} \mathrm{H}_{\mathrm{y}}, \mathrm{ppm}$} & \multicolumn{2}{|c|}{ NOx, ppm } \\
\hline & & & $\begin{array}{l}\text { before } \\
\text { neutra- } \\
\text { lizer }\end{array}$ & $\begin{array}{l}\text { after } \\
\text { neutra- } \\
\text { lizer }\end{array}$ & $\begin{array}{l}\% \\
\text { clea- } \\
\text { ning }\end{array}$ & $\begin{array}{l}\text { before } \\
\text { neutr } \\
\text { alizer }\end{array}$ & $\begin{array}{l}\text { after } \\
\text { neutr } \\
\text { alizer }\end{array}$ & $\begin{array}{l}\% \\
\text { cleani } \\
\text { ng }\end{array}$ & $\begin{array}{l}\text { before } \\
\text { neutrali } \\
\text { zer }\end{array}$ & $\begin{array}{l}\text { after } \\
\text { neutr } \\
\text { alizer }\end{array}$ & $\begin{array}{l}\% \\
\text { clean } \\
\text { ing }\end{array}$ \\
\hline 460 (1) & 110 & 491 & 0.085 & 0.085 & 0.0 & 0.0 & 0.0 & 0.0 & 0.072 & 0.05 & 30.6 \\
\hline $490(2)$ & 128 & 553 & 0.15 & 0.047 & 69.7 & 0.48 & 0.02 & 58.4 & 0.026 & 0.02 & 23.1 \\
\hline $570(3)$ & 144 & 673 & 0.145 & 0.09 & 38.0 & 0.49 & 0.02 & 59.3 & 0.072 & 0.05 & 30.6 \\
\hline $660(4)$ & 156 & 573 & 0.152 & 0.052 & 65.8 & 0.48 & 0.02 & 58.4 & 0.068 & 0.03 & 55.9 \\
\hline $750(5)$ & 171 & 843 & 0.150 & 0.02 & 78.7 & 0.20 & 0.0 & 100 & 0.064 & 0.026 & 61.8 \\
\hline $420(1)$ & 94 & 491 & 0.080 & 0.05 & 37.5 & 0.37 & 0.02 & 334 & 0.08 & 0.05 & 37.5 \\
\hline $490(2)$ & 120 & 553 & 0.125 & 0.085 & 2.0 & 0.37 & 0.02 & 409 & 0.05 & 0.02 & 69.0 \\
\hline $580(3)$ & 134 & 673 & 0.157 & 0.045 & 71.4 & 0.36 & 0.03 & 259 & 0.09 & 0.03 & 68.7 \\
\hline $660(4)$ & 155 & 573 & 0.165 & 0.060 & 64.0 & 0.34 & 0.04 & 100 & 0.05 & 0.04 & 20.0 \\
\hline $740(5)$ & 174 & 843 & 0.215 & 0.080 & 63.0 & 0.44 & 0.02 & 100 & 0.05 & 0.03 & 51.8 \\
\hline 420 (1) & 81 & 493 & 0.083 & 0.072 & 13.2 & 0.67 & 0.40 & 40.5 & 0.08 & 0.06 & 27.5 \\
\hline 485 (2) & 121 & 551 & 0.072 & 0.475 & 34.5 & 0.37 & 0.32 & 14.0 & 0.04 & 0.03 & 19.1 \\
\hline $580(3)$ & 128 & 578 & 0.137 & 0.067 & 51.3 & 0.42 & 0.27 & 35.4 & 0.09 & 0.04 & 58.4 \\
\hline $660(4)$ & 147 & 493 & 0.152 & 0.110 & 27.9 & 0.24 & 0.20 & 92.0 & 0.10 & 0.05 & 56.6 \\
\hline 750 (5) & 164 & 578 & 0.212 & 0.021 & 100 & 0.64 & 0.06 & 100 & 0.06 & 0.002 & 100 \\
\hline
\end{tabular}


which is formed in diesel combustion gases consists - are the particles of spherical shape with a diameter of $150-1,700 \AA$ with a specific surface area to $70.0-76.0 \mathrm{M}^{2} / \mathrm{g}$. Already in the course of combustion there is a coagulation of soot particles and formation of secondary and tertiary structures. Soot in the fulfilled gases of diesels represents formations of irregular shape. In the process of expansion

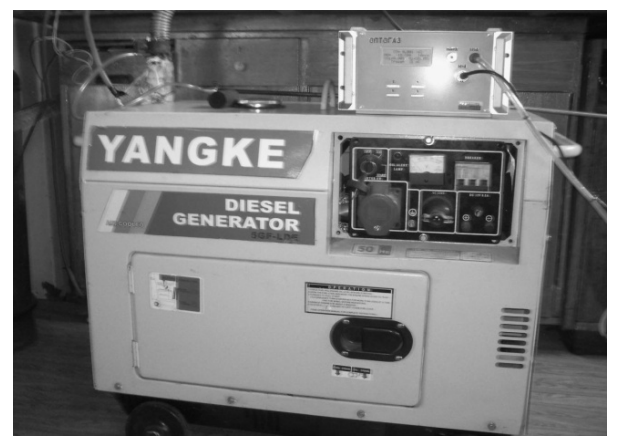

Fig. 3: The catalytic unit (the stand) on the basis of diesel generator of gases in the diesel cylinder to soot particles oxygen enters (due to gas movement and diffusion of oxygen), i.e. the favorable conditions for a soot burnup are created. The researches of formation and burnup of soot in the cylinder of the diesel engine executed by method of a spectral analysis ${ }^{20-22}$ show that the considerable proportion of soot burns out in the course of expansion. Isolation of soot from the exhaust gases of diesel engines depends, probably from both the process of formation and the process of its burning. Formation of soot can happen in places where there is excess fuel or at hit of streams of fuel on rather cold walls of the cylinder. The solid particles of soot moving along the channels of the catalyst used in the tests function as an abrasive material on the catalyst surface, thereby partly carrying away an active phase of catalyst. On the other hand, part of them is adsorbed on the surface of the catalyst, reducing its working surface. Nevertheless, the studied Pt- and Pd-containing catalysts in these conditions within

Table 2: Results of the analysis of toxiferous emissions on the diesel generator with use of $3.0 \%$ catalyst on the basis of $\mathrm{Mn}$ and $\mathrm{Ni}$ oxides

\begin{tabular}{|c|c|c|c|c|c|c|c|}
\hline \multirow{3}{*}{$\begin{array}{l}\text { Power } \\
\text { consum. } \\
\text { ption, kVA }\end{array}$} & \multirow{3}{*}{$\begin{array}{l}\text { The temperature of , } \\
\text { exhaust gases } \\
\mathrm{K}\end{array}$} & \multicolumn{6}{|c|}{ The content of toxic componentsin the exhaust gas, ppm } \\
\hline & & \multicolumn{2}{|c|}{$\mathrm{CO}$} & \multicolumn{2}{|c|}{$\mathrm{C}_{\mathrm{x}} \mathrm{H}_{\mathrm{y}}$} & \multicolumn{2}{|c|}{$\mathrm{NO}_{\mathrm{x}}$} \\
\hline & & $\begin{array}{l}\text { Before } \\
\text { catalyst }\end{array}$ & $\begin{array}{l}\text { After } \\
\text { catalyst }\end{array}$ & $\begin{array}{l}\text { Before } \\
\text { catalyst }\end{array}$ & $\begin{array}{l}\text { After } \\
\text { catalyst }\end{array}$ & $\begin{array}{l}\text { Before } \\
\text { catalys }\end{array}$ & $\begin{array}{l}\text { After } \\
\text { catalyst }\end{array}$ \\
\hline Idling (0) & 298 & 0.036 & 0.035 & 65.0 & 60.0 & 13.2 & 13.2 \\
\hline 2.0 & 533 & 0.030 & 0.00 & 81.0 & 20.0 & 17.4 & 10.8 \\
\hline 3.0 & 573 & 0.021 & 0.00 & 89.0 & 3.5 & 19.0 & 7.6 \\
\hline 4.0 & 698 & 0.014 & 0.00 & 111.0 & 10.0 & 23.0 & 8.0 \\
\hline
\end{tabular}

Table 3: Results of the analysis of toxic emissions of diesel generator by using a catalyst containing $0.2 \% \mathrm{Pd}$

\begin{tabular}{|c|c|c|c|c|c|c|c|}
\hline \multirow{3}{*}{$\begin{array}{l}\text { Power } \\
\text { consum- } \\
\text { ption, } \\
\text { kVA }\end{array}$} & \multirow{3}{*}{$\begin{array}{l}\text { Temperature of } \\
\text { exhaust gases, } \mathrm{K}\end{array}$} & \multicolumn{6}{|c|}{ The content of toxic components in the exhaust gas, ppm } \\
\hline & & \multicolumn{2}{|c|}{$\mathrm{co}$} & \multicolumn{2}{|c|}{$\mathrm{C}_{\mathrm{x}} \mathrm{H}_{\mathrm{y}}$} & \multicolumn{2}{|c|}{$\mathrm{NO}_{\mathrm{x}}$} \\
\hline & & $\begin{array}{l}\text { Before } \\
\text { catalyst }\end{array}$ & $\begin{array}{l}\text { After } \\
\text { catalyst }\end{array}$ & $\begin{array}{l}\text { Before } \\
\text { catalyst }\end{array}$ & $\begin{array}{l}\text { After } \\
\text { catalyst }\end{array}$ & $\begin{array}{l}\text { Before } \\
\text { catalyst }\end{array}$ & $\begin{array}{l}\text { After } \\
\text { catalyst }\end{array}$ \\
\hline Idling (0) & 298 & 0.033 & 0.033 & 67.2 & 55.1 & 14.5 & 14.1 \\
\hline 2.0 & 533 & 0,03 & 0.002 & 79.6 & 62.3 & 17.8 & 8.3 \\
\hline 3.0 & 573 & 0.02 & 0.00 & 92.1 & 6.4 & 21.0 & 6.4 \\
\hline 4.0 & 698 & 0.015 & 0.00 & 107.0 & 4.2 & 22.6 & 7.0 \\
\hline
\end{tabular}


1 month practically did not lose their effectiveness in oxidizing reactions of $\mathrm{CO}$, hydrocarbons and reduction of nitrogen oxides. This indicates a high adhesion strength and chemical resistance to the products of diesel engine exhaust.

Tests of catalysts for the purpose of determination of stability of catalysts to the poisons containing in exhaust gases of the diesel engine are carried out. During research of three types of catalysts it was found that Pt-containing catalyst $(0.1 \%$ of $\mathrm{Pt})$ on the basis of alumina at a temperature of exhaust gases $573 \mathrm{~K}$ oxidizes for $100 \% \mathrm{CO}$ and for $92.0 \%$ hydrocarbons and partially to $17.0 \%$ transform nitrogen oxides. Further increase of loading of the engine does not influence a rate of oxidation of $\mathrm{CO}$ and hydrocarbons. Similarly also $\mathrm{Pd}$ - containing $(0.2 \%)$ catalyst on alumina behaves, oxidizing $\mathrm{CO}$ for $100 \%$ and $\mathrm{C}_{x} \mathrm{H}_{y}$ for $90.0 \%$ at $573 \mathrm{~K}$. At the same time, the Pt catalyst prepared on the basis of alumina and $10.0 \%$ zeolite HY, showed significantly higher activity for neutralizing of toxic diesel engine emissions. Thus, at $573 \mathrm{~K}$ the level of toxic emissions decreasing on CO reaches $100 \%$,

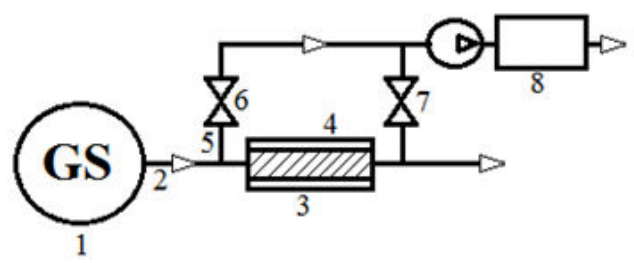

Fig.4: Principle schema of the stand on the basis of diesel generator:

1 - the diesel generator; 2 - the exhaust pipe; 3the catalytic reactor; 4- the catalyst sample;

5- the vapour sensor; 6, 7 - sampling valves before and after the catalyst; 8 - a gas analyzer on $\mathrm{C}_{x} \mathrm{H}_{y}-100 \%$, on $\mathrm{NO}_{x}-48.0 \%$. A further increase in the load contributes to lower content of $\mathrm{NO}_{x}$ to $22.0 \%$, without reducing of the level of purification for $\mathrm{CO}$ and $\mathrm{C}_{x} \mathrm{H}_{y}$

By method of the X-ray phase analysis and $\mathrm{EM}^{14}$ the physical and chemical researches of catalysts were carried out. It was found that the oxide catalysts represent spinels with a cubic lattice with $\mathrm{NiMnO}_{4}$ peaks $2 \AA$, $52 \AA$, $148 \AA$, $203 \AA$. There are

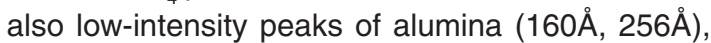
in the catalysts based on manganese are formed the particles which are finely dispersed, uniformly distributed on the surface of the carrier. X-ray analysis showed Pd and Pt scattering spectrum, which indicates a high dispersion of the metal.

In fig. 5 the nano-dimensional particles of Pt and Pd obtained at synthesis of the active phase of catalysts by introduction of the corresponding salts to an aqueous solution of PEG are shown. Pictures are made with use of electron microscope EM-125 K. Pt particle sizes are 7-8 nm, Pd-11 nm.

By use of a method of TPD of ammonia the acid properties of the prepared platinum and palladium catalysts were studied ${ }^{14}$. The total concentration of acid centers Pt- and Pd-promoted catalysts of nickel and manganese oxides, higher than in the initial alumina-platinum and palladium catalysts. Thus, Pt-and Pd-containing catalysts at close values of the total concentration of the acid centres 660.0-620.0 $\mu \mathrm{mol} / \mathrm{g}$ are characterized by a distinguished ratio of the centres of different force, that, apparently, determines distinctions in their catalytic properties. In fig. 6 the comparative diagrams for catalysts with various concentrations of the acid centres of different force were shown.

Table 4: Investigation of thermal stability Pt- and Pd-containing catalysts on diesel generator

\begin{tabular}{llllllll}
\hline The catalyst & $\begin{array}{l}\text { Exhaust } \\
\text { gases }\end{array}$ & $\begin{array}{l}\text { Initial degree } \\
\text { of cleaning, } \%\end{array}$ & \multicolumn{2}{l}{ Duration of testing, $\mathbf{h}}$. \\
\cline { 5 - 8 } & & & $\mathbf{5}$ & $\mathbf{1 0}$ & $\mathbf{2 5}$ & $\mathbf{5 0}$ & $\mathbf{1 0 0}$ \\
\hline \multirow{2}{*}{$0.1 \% \mathrm{Pt}+\mathrm{Me}$} & $\mathrm{CO}$ & 100 & 100 & 100 & 100 & 100 & 100 \\
& $\mathrm{C}_{\mathrm{x}} \mathrm{H}_{\mathrm{y}}$ & 95.0 & 95.3 & 94.2 & 94.3 & 94.2 & 94.7 \\
& $\mathrm{NO}_{\mathrm{x}}$ & 60.5 & 60.0 & 61.0 & 59.8 & 59.7 & 59.6 \\
$0.2 \% \mathrm{Pd}+\mathrm{Me}$ & $\mathrm{CO}$ & 100 & 100 & 100 & 100 & 100 & 100 \\
& $\mathrm{C}_{\mathrm{x}} \mathrm{H}_{\mathrm{y}}$ & 90.0 & 90.2 & 90.0 & 88.7 & 88.8 & 88.4 \\
& $\mathrm{NO}_{x}$ & 48.2 & 42.9 & 48.1 & 48.1 & 46.8 & 46.4 \\
\hline
\end{tabular}


Catalysts on basis $\mathrm{Pt} / \mathrm{Ni}-\mathrm{Mn} / \mathrm{Al}_{2} \mathrm{O}_{3}$ are characterized by the greatest concentration of the strong acid centres $(280.0 \mu \mathrm{mol} / \mathrm{g})$, for $\mathrm{Pd} / \mathrm{Ni}-\mathrm{Mn} / \mathrm{Al}_{2} \mathrm{O}_{3}$ catalyst the greatest concentration of the weak acid centres $-250.0 \mu \mathrm{mol} / \mathrm{g}$.

It was found, that in manganese catalysts on basis PEG were formed the particles which were finely divided, in regular intervals distributed on a surface of the carrier and that fact was proved to be true as well results of XRD analysis. At transition to the catalysts on the basis of acetate, and, in particular, to catalysts on the basis of nitrates of manganese, there was an integration of particles that was, apparently, the reason of decrease in activity of manganese catalysts in reaction of oxidation of hydrocarbons and $\mathrm{CO}$.
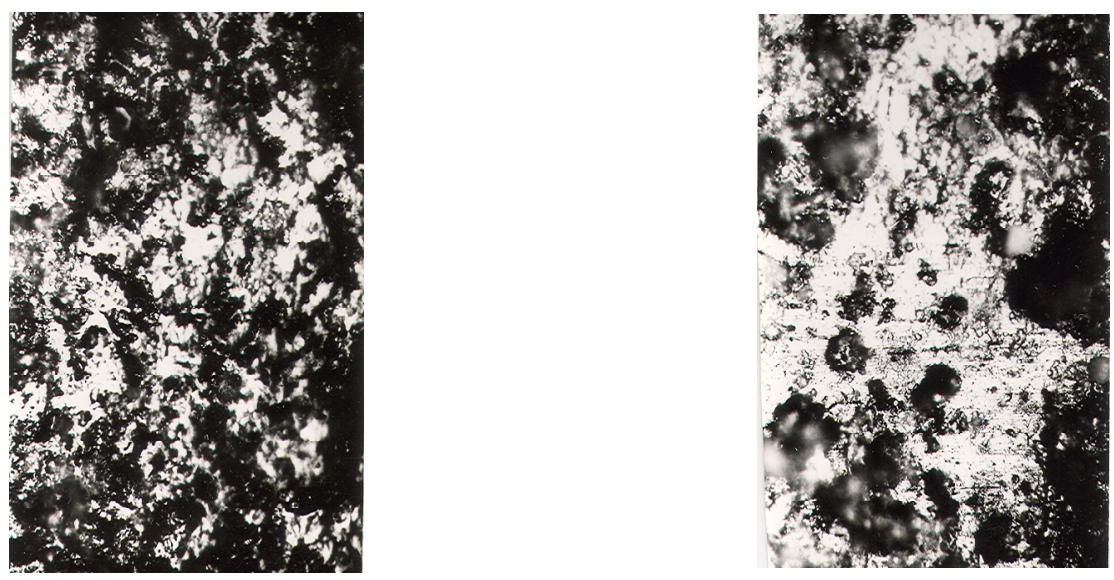

Fig. 5: The nanosized particles (300, 000 magnification): Pt (a), Pd (b)

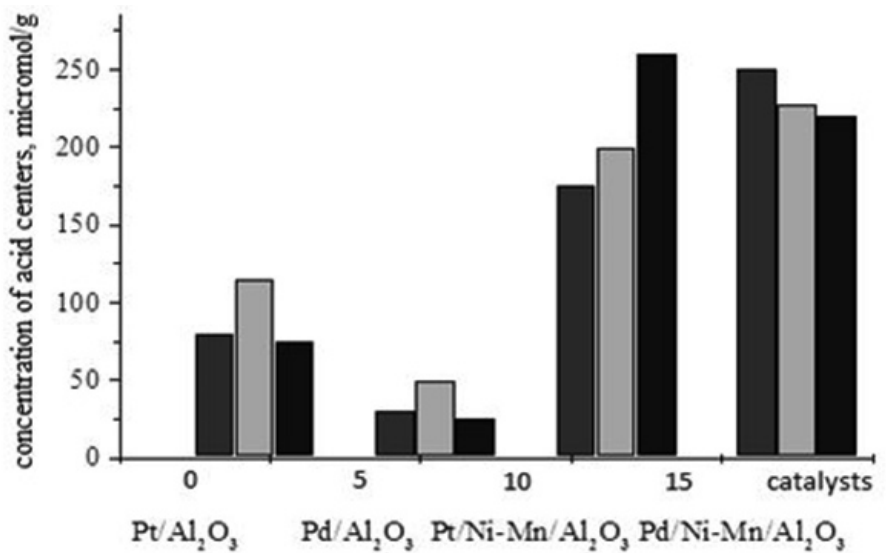

- weak centers

- centers of medium strength

- strong centers

Fig. 6: Effect of chemical composition of neutralizers on the distribution acid centers of various strength 


\section{REFERENCES}

1. Mathieu, O.; Lavy J.; Jeudy E. J.Topics in Catalysis 2009, 52(13-20), 1893-1897

2. O'Neill, B.C. J.Science 2002, 5575, 1971.

3. Rauch, S.; Harold, H.F.; Barbante, C.; Masanori, O.; Morrison, G.M.; PeuckerEhrenbrink, B.; Wass, U. J.Environ.Sci. Technol. 2005, 1, 8156

4. Takami, A.; Ichikawa, T. J. Zeolites. 1995, 15(3), 283

5. Val'dberg, A.Yu; Kosogorova, T.O.; Tsedilin, A.N.; Pokrovskii, D.D.; Yakimychev, A.A.; J.Chemical and Petroleum Engineering. 2007, 5-6, 287-291

6. Awofeso, N. American Journal of Respiratory and Critical Care Medicine. 2011, 10, 1437

7. Giraldo, L.; Moreno-Pirajan, J.C. Orient. J. Chem. 2014, 30(2), 451-461

8. Ko ${ }^{3}$ odziej, A.; £ojewska, J. Chapter in: New and Future Developments in Catalysis. 2013, 257-279

9. Tsai, J.-H. J.Aerosol and Air quality research. 2015.

http://dx.doi.org/10.4209/aaqr.2015.07.0482.

10. Kramer, M.; Schmidt, T.; Stowe, K.; Maier, W.F. J.Appl.Catalysis A: General. 2006, 302, 257-263

11. Yang, S.; He, L-Y. J.Energy \& Environment. 2016. http://dx.doi. org/10.1177/0958305x15627545.

12. McGrath, M. Four major cities move to ban diesel vehicles by 2025. http://www.bbc.com/ news/science-environment-38170794.

13. Sendilvelan, S.; Bhaskar, K. Rasayan J.Chem.
2016, 9(4), 692-696

14. Sassykova, L.R.; Massenova, A.T.; Gilmundinov, Sh.A.; Bunin, V.N.; Rakhmetova, K.S. DGMK, Tagungsbericht, 2014, 3, 181188

15. Sassykova, L.; Gil'mundinov, Sh.; Nalibayeva, A.; Bogdanova, I. Rev. Roum. Chim. 2017, 62(2), 107-114

16. Sassykova, L.R.; Ussenov A.; Massenova, A.T.; Gil'mundinov, Sh.A.; Rakhmetova, K.S.; Bunin, V.N.; Basheva, Zh.T.; Kalykberdiyev, M.K. Int. J. Chem. Sci. 2016, 14(1), 206-212

17. Burdeinaya, T.N.; Matyshak, V.A.; Tret'yakov, V.F.; Glebov, L.S.; Zakirova, A.G.; Carvajal, G., Villanueva, A.M.E. J.Appl. Catalysis B:Environmental. 2007, 1-4, 128.

18. Lee, B.Y.; Inoue, Y.; Yasimori, I. J Bull Chem Soc Jpn. 1981, 54, 3711.

19. In, B.D.; Kim, H.; Son, J.; Lee, K. Intern. J. Heat and Mass Transf. 2015, 86, 667 - 680.

20. Nalibayeva, A.; Sassykova, L.R.; Kotova, G.N.; Bogdanova, I.O. News of National Academy of RK, series of Chemistry and Technology. 2016, 419(5), 55-64

21. Sassykova, L.R.; Nalibayeva, A.; Gil'mundinov, Sh.A. Bulgarian Chemical Comm. 2017, 49(3)

22. Baiseitov, D.A.; Tulepov, M.I.; Tursynbek, S.; Sassykova, L.R.; Nazhipkyzy, M.; Gabdrashova,Sh.E.; Kazakov,Y.V.; Pustovalov,I.O.; Abdrakova, F.Y.; Mansurov, Z.A.; Dalton, A.B. Rasayan J. Chem.2017, 10(2), $344-348$. 